\title{
The first patient with a pure 1 p36 microtriplication associated with severe clinical phenotypes
}

Fang Xu ${ }^{1,2}$, Ya-Nan Zhang ${ }^{1}$, De-Hua Cheng ${ }^{1,2}$, Ke Tan ${ }^{1,3}$, Chang-Gao Zhong ${ }^{1,2}$, Guang-Xiu Lu ${ }^{1,2,3}$, Ge Lin ${ }^{1,2,3}$ and Yue-Qiu Tan ${ }^{1,2^{*}}$

\begin{abstract}
Background: Copy Number Variants (CNVs) is a new molecular frontier in clinical genetics. CNVs in 1p36 are usually pathogenic and have attracted the attention of cytogeneticists worldwide. None of 1 p36 triplication has been reported thus far.

Results: We present three patients with CNVs in 1p36. Among them one is the first 1 p36 tetrasomy due to a pure microtriplication and the other two are 1p36 microdeletion. Traditional chromosome G-banding technique showed a normal karyotype. Single nucleotide polymorphism (SNP) microarray analysis combined with multiplex ligation-dependent probe amplification (MLPA) and fluorescence in situ hybridization (FISH) were used to identify and confirm the chromosome microdeletion/microtriplication. The facial dysmorphisms of the patient with 1 p36 tetrasomy differed from those two patients with 1 p36 monosomy. The expression levels of B3GALT6, MIB2, PEX10 and PANK4 in the blood were determined, and differential expressions were observed between the patients and controls.

Conclusions: Our study shows the first case of 1p36 tetrasomy due to a pure microtriplication in a patient with severe intellectual disability and seizures. The study provides a new resource for studying the mechanisms of microtriplication formation, and provides an evidence that overexpression of the specific genes might be related the specific phenotype of 1 p36 microtriplication.
\end{abstract}

Keywords: Copy number variations, 1 p36 microtriplication, 1p36 microdeletion, Single nucleotide polymorphism microarray

\section{Background}

Copy Number Variants (CNVs) is a new molecular frontier in clinical genetics [1]. Some CNVs are associated with genomic disorders with extreme phenotypic heterogeneity, which brings challenges in genetic diagnosis, counseling, and management [2]. CNVs in 1p36 include microdeletion and microduplication. $1 \mathrm{p} 36$ microdeletion is relatively common, with an incidence of $\sim 1$ in 5000 newborns $[3,4]$. Its main phenotypes include intellectual disability, developmental delay, prominent forehead, lowset ears, long philtrum, pointed chin, short feet, hearing loss, seizures, hypomyotonia, feeding difficulties, speech

\footnotetext{
* Correspondence: tanyueqiu@csu.edu.cn

${ }^{1}$ Institute of Reproduction and Stem Cell Engineering, Central South University, $110 \#$ Xiangya Road, Changsha, Hunan 410078, PR China ${ }^{2}$ Reproductive and Genetic Hospital of Citic-Xiangya, Changsha, Hunan 410078, PR China

Full list of author information is available at the end of the article
}

delay, strabismus, heart defects, obesity, skeletal anomalies, renal and genital abnormalities $[3,4]$.

In contrast, $1 \mathrm{p} 36$ microduplication is rare, with only two cases of "pure" 1 p36 microduplication having been reported, one affecting a 6-month-old male infant and the other, a 17-year-old male patient [5]. The major phenotypic features in these two patients were hypotonia, severe psychomotor delay, intellectual disability, developmental delay and speech defects.

Here, we present three patients with CNVs in 1 p36. Among them one is the first $1 \mathrm{p} 36$ tetrasomy due to a pure microtriplication and the other two are $1 \mathrm{p} 36$ microdeletion. Changes in chromosome copy numbers were detected and confirmed by SNP array, MLPA and FISH analyses. Expression levels of 4 genes (B3GALT6, MIB2, PEX10 and PANK4) mapping to the deleted and 

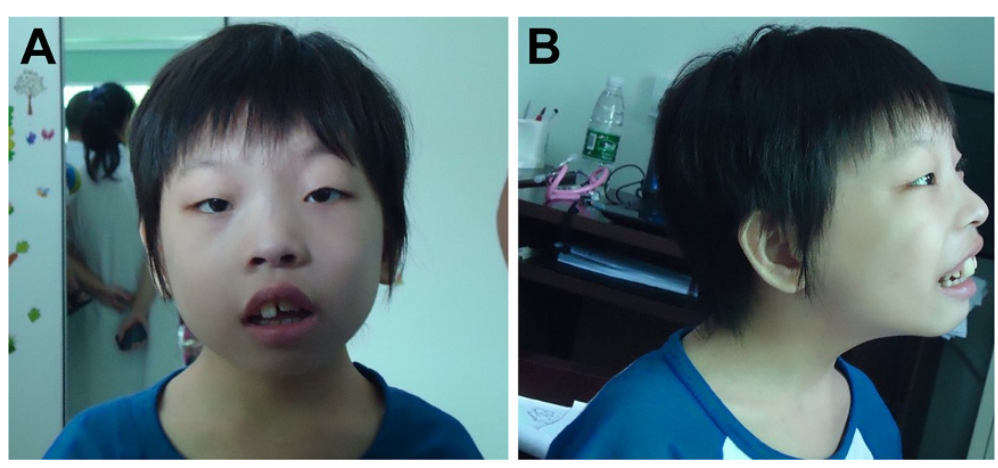

Figure 1 Clinical photographs of the patient with 1 p36 triplication. (A) Front view of the face. (B) Lateral view of the face. The major facial phenotype included strabismus, hypertelorism, low hairline, ear malformations, broad nasal bridge, wide mouth, thick lips and prominent incisors.

triplicated segments were determined by quantitative PCR analysis, which showed that transcript levels correlated with altered DNA copy numbers, indicating that the observed phenotypes resulted from gene-dosage effects.

\section{Case presentation}

An eight-year-old female patient was brought to our clinic by her non-sanguineous parents due to severe intellectual disability and seizures. The patient, the first and only child of a 24-year-old father and a 22-year-old

Table 1 Features presented in patients with 1 p36 micro-rearrangement

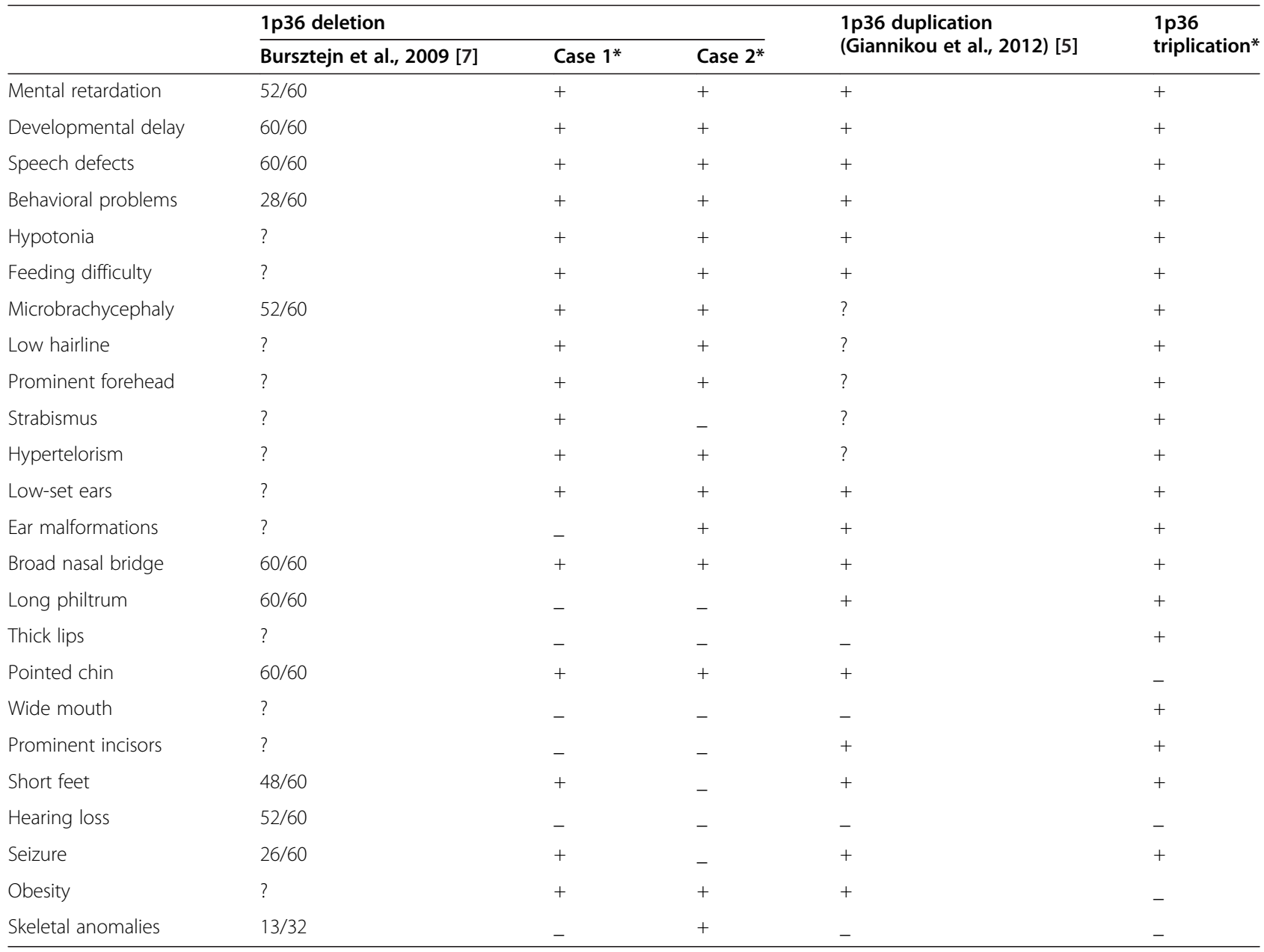

*: presented in this study.

"+" : present; "_": absent; "?": uncertain. 

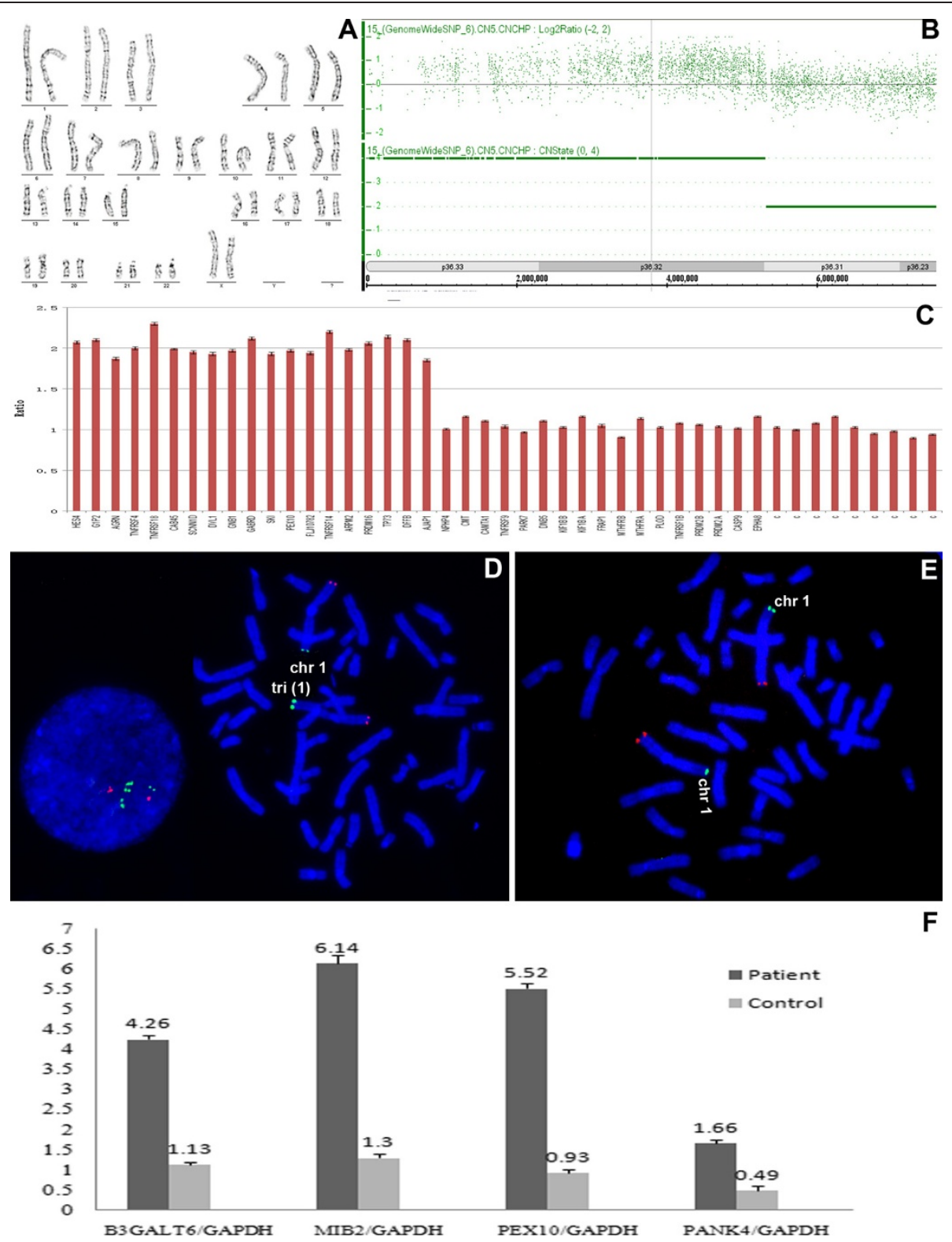

Figure 2 Copy number variants analysis of the patient: (A) “Normal” high-resolution karyotype. (B) A SNP microarray analysis detected an approximately 5.28-Mb triplication in the short arm of chromosome 1. (C) MLPA result using SALSA kit P147-B1 of MRC Holland, showing a triplication included all probes from ISG15 up to AJAP1(RPH are approximately 2.0). (D) FISH results of the patient. Two red signals with the similar strength were presented in the long arm of chromosome 1 by the control probe TelVysion 1q. However, by the testing probe TelVysion 1p, the green hybridization signal in one $1 p$ was obviously stronger than that in the other $1 p$, and in interphase nucleus, four green signals could be seen. (E) FISH image of the parents of the patient showed normal appearance, indicating that the 1p partial triplication is de novo (the FISH image of mother didn't shown). (F) Quantitative PCR analysis showed the patient had 3 to 6 times as higher expression levels than control for the four genes B3GALT6, MIB2, PEX10, PANK4 in the blood.

mother, was born at full term by a normal delivery after an uneventful pregnancy. She had suffered from feeding problems in infancy as well as a medical history of severe seizures. On top of that, she could also catch a cold and fever very easily, and had once been hospitalized because of pneumonia. She developed delay obviously at each developmental milestone, including gross motor, fine motor, language, cognitive development and social behavior. For instance, she was capable of walking until 2 years and half and saying "dada" and "mama" until 2 years. She undergone surgery for congenital left eyelid ptosis at the age of 3 years. Now she was 8 years old, and according to our physical examination, her weight, height and body mass index (BMI) represented were 
$18 \mathrm{~kg}, 108.5 \mathrm{~cm}$, and $15.29 \mathrm{~kg} / \mathrm{m}^{2}$ (25th-50th centiles) [6], respectively; Also, she has got microcephaly (head circumference, $49.6 \mathrm{~cm}$; reference value, $52.19 \mathrm{~cm}$ ). Facial dysmorphism, with strabismus, hypertelorism, low hairline, ear malformations, broad nasal bridge, wide mouth, thick lips and prominent incisors could be observed (Figure 1; Table 1). The child could understand some simple sentences, whose expressive ability to speak simple words and sentences is extremely poor. It can be seen that she had behavioral abnormalities, unable to take care of herself, no to mention getting focused and controlling herself well. However, ultrasonography of the uterus, liver, gallbladder, spleen, pancreas, kidneys and heart showed no abnormalities.

Other two 8-year-old female patients with $1 \mathrm{p} 36$ microdeletion syndrome were also identified in the study by FISH and MLPA techniques (Additional file 1).

\section{Results}

Karyotype analysis at 550 band resolution showed the proband with a female karyotype $(46, \mathrm{XX})$, without any suggestion of chromosome abnormality (Figure 2A). Her parents also presented normal karyotype.

Single nucleotide polymorphism (SNP) microarray analysis by Affymetrix SNP 6.0 was performed as our previous report $[8,9]$. The result showed a pure $5.28 \mathrm{Mb}$ microtriplication at 1p36.33p36.32, and the karyotype could be expressed as 46, XX.arr[hg19]1p36.33p36.32(1-5,280.000) × 4 (Figure 2B), which was considered as a pathogenic CNV according to the available databases including Database of Genomic Variant (http://projects.tcag.ca/variation/), DECIPHER (https:// decipher.sanger.ac.uk/), ECARUCA (http://umcecaruca01. extern.umcn.nl:8080/ecaruca/ecaruca.jsp), OMIM (http:// www.omim.org/), and pubmed (http://www.pubmed.gov/).

Multiplex ligation dependent probe amplification (MLPA) analysis using the SALSA kit P147-B1 (MRC-Holland, Amsterdam, the Netherlands, see http://www.mlpa.com) confirmed the microtriplication for chromosome $1 \mathrm{p}$ (Figure 2C), including all probes from ISG15 up to AJAP1, which was consistent with the SNP microarray result. The SNP array result was also confirmed by Fluorescent in situ hybridization (FISH) with two subterminal probes TelVysion 1p (SpectrumGreen labeled) and TelVysion 1q (SpectrumOrange labeled) which were purchased from Abbott-Vysis, Inc (Downers Grove, IL, USA) (Figure 2D and 2E).

Quantitative PCR analysis showed that transcript levels in the blood correlate with altered DNA copy numbers. For the selected 4 OMIM genes B3GALT6 (betaGal beta 1,3-galactosyltransferase polypeptide 6), MIB2 (mindbomb E3 ubiquitin protein ligase 2), PEX10 (peroxisomal biogenesis factor 10), PANK4 (pantothenate kinase 4), which are situated in the $1 \mathrm{p} 36.33 \mathrm{p} 36.32$ region and were expression in blood, the ratios of the patient to the controls (a healthy 8-year-old female sample) showed significant differences (Figure 2F), indicating upregulated and deregulated expression respectively.

\section{Discussion}

Here, we report the first case of a pure 1p36.33p36.32 tetrasomy resulting from a de novo microtriplication detected on SNP microarray and confirmed by MLPA and FISH analyses. Our results provide a new case for exploring the formation mechanism of 1 p36 microtriplication and the molecular etiology of the patient.

The most common mechanism underlying CNVs is non-allelic homologous recombination and not nonhomologous end joining mediated by low copy repeats during meiosis [10]. Cytogenetically invisible tetrasomy due to a chromosome segment microtriplication is a very complex and rare CNV. Till date, only a few triplications have been reported, including $2 \mathrm{q} 11.2 \rightarrow \mathrm{q} 21$ [11], 2q12.3 $\rightarrow$ q13 [12], 3q25.3 $\rightarrow$ q29 [13], 7q11.23 [14], 13q14 [15], 15q11 $\rightarrow$ q13 [16], 17p11.2 $\rightarrow$ p12 [17] and 22q11.2 [18]. A case of "pure" 1p36 tetrasomy has not yet been reported, although complex rearrangements resulting in deletions, duplications and/or triplications for portions of $1 \mathrm{p} 36$ have been reported elsewhere, along with postulated mechanisms of formation $[19,20]$. Thus, our study provides a new resource for studying the mechanisms of microtriplication formation.

In general, a tetrasomy causes a similar but more severe phenotype than a trisomy of the same region. For example, 7q11.23 duplication causes Williams-Beuren syndrome (WBS). The first patient reported to have a 7q11.23 triplication had a similar but more severe WBS phenotype, with severe developmental delay, severe retardation in language and speech, behavioral problems, autistic features and mild dysmorphic features [14]. Girirajan et al. described a patient with a large 17p11.2p12 duplication, partial 17p11.2p12 triplication and 17q11. 2q12 deletion [17]. The severe phenotypic features in the patient included heart defects, seizure, thoracolumbar fistula and malignant hyperthermia. They attributed the disease-causing events to an increased copy number of dosage-sensitive genes in $17 \mathrm{p} 11.2 \mathrm{p} 12$. We found that the clinical phenotypes of our patient with microtriplication 1 p36 were similar to our other two patients with monosomy $1 \mathrm{p} 36$ (Table 1). These phenotypes included intellectual disability, developmental delay, feeding difficulties, hyperactivity and seizures. The two reported cases of 1 p36 trisomy [5] had similar phenotypes to those in our patients with $1 \mathrm{p} 36$ tetrasomy and $1 \mathrm{p} 36$ deletion, but the clinical symptoms (psychomotor delay, intellectual disability, speech defects) were relatively mild.

The reason why $1 \mathrm{p} 36$ triplication causes more severe phenotype than $1 \mathrm{p} 36$ duplication, the dosage effect of gene expression in this region would be one of the possibilities. For example, craniosynostosis has been reported in patients 
with deletions and duplications/triplications of a gene on 1 p36 that plays a role in regulating cranial suture closure [21]. In this 1 p36 microtriplication patient, we found a de novo $5.28 \mathrm{Mb}$ microtriplication at 1p36.33p36.32, involving 152 genes and 49 OMIM morbid genes. We hypothesize that the dosage effect of gene is related with the clinical phenotype of the patient. We selected four OMIM genes B3GALT6, MIB2, PEX10, PANK4 which were expressed in the blood to test the hypothesis, and the results showed the patient had 3 to 6 times as higher expression levels than that in the control, which provided an evidence that overexpression of the specific genes might be related the specific phenotype of $1 \mathrm{p} 36$ microtriplication.

\section{Conclusions}

Our study shows the first case of 1p36 tetrasomy due to a pure microtriplication in a patient with severe intellectual disability and seizures. The study provides a new resource for studying the mechanisms of microtriplication formation, and provides an evidence that overexpression of the specific genes might be related the specific phenotype of 1p36 microtriplication.

\section{Consent}

Written informed consent was obtained from the parents of the patients for publication of this Case report and any accompanying images. A copy of the written consent is available for review by the Editors-in-Chief of this journal.

\section{Additional file}

Additional file 1: Two 1p36 microdeletion syndrome patients in the study.

\section{Competing interests}

The authors declare that they have no competing interests.

\section{Authors' contribution}

All authors read and approved the final manuscript. YQT designed the study and revised the manuscript. FX performed the MLPA and quantitative PCR, analyzed the data and wrote the paper. YNZ and CDH performed the FISH experiments and interpreted the results. KT performed the SNP experiments. CGZ reviewed all laboratory results and patient data. GL and GXL conceived the study and provided financial support.

\section{Acknowledgements}

We are grateful to the family who participated in this study. This work was supported by the grants from the Major State Basic Research Development Program of China (No. 2012CB944901) and National Natural Science Foundation of China (No. 81471432).

\footnotetext{
Author details

'Institute of Reproduction and Stem Cell Engineering, Central South University, 110\# Xiangya Road, Changsha, Hunan 410078, PR China. ${ }^{2}$ Reproductive and Genetic Hospital of Citic-Xiangya, Changsha, Hunan 410078, PR China. ${ }^{3}$ National Engineering and Research Center of Human Stem Cell, Changsha 410078, PR China.
}

Received: 31 July 2014 Accepted: 1 September 2014

Published online: 03 October 2014

\section{References}

1. Moreno-De-Luca D, Cubells JF: Copy number variants: a new molecular frontier in clinical psychiatry. Curr Psychiatry Rep 2011, 13:129-137.

2. Girirajan S, Rosenfeld JA, Coe BP, Parikh S, Friedman N, Goldstein A, Filipink RA, McConnell JS, Angle B, Meschino WS, Nezarati MM, Asamoah A, Jackson KE, Gowans GC, Martin JA, Carmany EP, Stockton DW, Schnur RE, Penney LS, Martin DM, Raskin S, Leppig K, Thiese H, Smith R, Aberg E, Niyazov DM, Escobar LF, El-Khechen D, Johnson KD, Lebel RR, et al: Phenotypic heterogeneity of genomic disorders and rare copy-number variants. N Engl J Med 2012, 367:1321-1331.

3. Gajecka M, Mackay KL, Shaffer LG: Monosomy 1p36 deletion syndrome. Am J Med Genet C: Semin Med Genet 2007, 145C:346-356.

4. Battaglia A, Hoyme HE, Dallapiccola B, Zackai E, Hudgins L, McDonaldMcGinn D, Bahi-Buisson N, Romano C, Williams CA, Brailey LL, Zuberi SM, Carey JC: Further delineation of deletion 1 p36 syndrome in 60 patients: a recognizable phenotype and common cause of developmental delay and mental retardation. Pediatrics 2008, 121:404-410.

5. Giannikou K, Fryssira H, Oikonomakis V, Syrmou A, Kosma K, Tzetis M, Kitsiou-Tzeli S, Kanavakis E: Further delineation of novel 1 p36 rearrangements by array-CGH analysis: narrowing the breakpoints and clarifying the "extended" phenotype. Gene 2012, 506:360-368.

6. Ma J, Wang Z, Song Y, Hu P, Zhang B: BMI percentile curves for Chinese children aged 7-18 years, in comparison with the WHO and the US Centers for Disease Control and Prevention references. Public Health Nutr 2010, 13:1990-1996.

7. Bursztejn AC, Bronner M, Peudenier S, Grégoire MJ, Jonveaux P, Nemos C: Molecular characterization of a monosomy $1 \mathrm{p} 36$ presenting as an Aicardi syndrome phenocopy. Am J Med Genet A 2009, 149A:2493-2500.

8. Cheng DH, Gong F, Tan K, Lu CF, Lin G, Lu GX, Tan YQ: Karyotype determination and reproductive guidance for short stature women with a hidden Y chromosome fragment. Reprod Biomed Online 2013, 27:89-95.

9. Tan YQ, Tan K, Zhang SP, Gong F, Cheng DH, Xiong B, Lu CF, Tang XC, Luo KL, Lin G, Lu GX: Single-nucleotide polymorphism microarray-based preimplantation genetic diagnosis is likely to improve the clinical outcome for translocation carriers. Hum Reprod 2013, 28:2581-2592.

10. Carvalho CM, Lupski JR: Copy number variation at the breakpoint region of isochromosome 17q. Genome Res 2008, 18:1724-1832.

11. Cooke LB, Richards H, Lunt PW, Burvill-Holmes L, Howell RT, McDermott A: Duplication 2 (q11.2 $\rightarrow$ q21): a previously unreported abnormality. J Med Genet 1995, 32:825-826.

12. Mercer CL, Browne CE, Barber JC, Maloney VK, Huang S, Thomas NS, Foulds N, MacLachlan N: A complex medical phenotype in a patient with triplication of $2 q 12.3$ to $2 q 13$ characterized with oligonucleotide array CGH. Cytogenet Genome Res 2009, 124:179-186.

13. Ounap K, llus T, Bartsch O: A girl with inverted triplication of chromosome 3 q25.3/q29 and multiple congenital anomalies consistent with $3 q$ duplication syndrome. Am J Med Genet A 2005, 134:434-438.

14. Beunders $G$, van de Kamp JM, Veenhoven RH, van Hagen JM, Nieuwint AW, Sistermans EA: A triplication of the Williams-Beuren syndrome region in a patient with mental retardation, a severe expressive language delay, behavioural problems and dysmorphisms. J Med Genet 2010, 47:271-275

15. Brecevic L, Basaran S, Dutly F, Röthlisberger B, Schinzel A: Tandem triplication of chromosome $13 q 14$ with inverted interstitial segment in a 4 year old girl. J Med Genet 2000, 37:964-967.

16. Roberts SE, Dennis NR, Browne CE, Willatt L, Woods G, Cross I, Jacobs PA, Thomas S: Characterisation of interstitial duplications and triplications of chromosome 15q11-q13. Hum Genet 2002, 110:227-234.

17. Girirajan S, Williams SR, Garbern JY, Nowak N, Hatchwell E, Elsea SH: $17 p 11.2$ p12 triplication and del(17)q11.2q12 in a severely affected child with dup(17)p11.2p12 syndrome. Clin Genet 2007, 72:47-58.

18. Yobb TM, Somerville MJ, Willatt L, Firth HV, Harrison K, MacKenzie J, Gallo N, Morrow BE, Shaffer LG, Babcock M, Chernos J, Bernier F, Sprysak K, Christiansen J, Haase S, Elyas B, Lilley M, Bamforth S, McDermid HE: Microduplication and triplication of $22 q 11.2$ a highly variable syndrome. Am J Hum Genet 2005, 76:865-876.

19. Gajecka M, Yu W, Ballif BC, Glotzbach CD, Bailey KA, Shaw CA, Kashork CD, Heilstedt HA, Ansel DA, Theisen A, Rice R, Rice DP, Shaffer LG: Delineation of mechanisms and regions of dosage imbalance in complex rearrangements of 1 p36 leads to a putative gene for regulation of cranial suture closure. Eur J Hum Genet 2005, 13:139-149. 
20. D'Angelo CS, Gajecka M, Kim CA, Gentles AJ, Glotzbach CD, Shaffer LG,

Koiffmann CP: Further delineation of nonhomologous-based recombination and evidence for subtelomeric segmental duplications in $1 \mathrm{p} 36$ rearrangements. Hum Genet 2009, 125:551-563.

21. D'Angelo CS, Kohl I, Varela MC, de Castro Cl, Kim CA, Bertola DR, Lourenço CM, Koiffmann CP: Extending the phenotype of monosomy 1 p36 syndrome and mapping of a critical region for obesity and hyperphagia. Am J Med Genet A 2010, 152A:102-110.

doi:10.1186/s13039-014-0064-9

Cite this article as: Xu et al: The first patient with a pure $1 \mathrm{p} 36$

microtriplication associated with severe clinical phenotypes. Molecular

Cytogenetics 2014 7:64.

\section{Submit your next manuscript to BioMed Central and take full advantage of:}

- Convenient online submission

- Thorough peer review

- No space constraints or color figure charges

- Immediate publication on acceptance

- Inclusion in PubMed, CAS, Scopus and Google Scholar

- Research which is freely available for redistribution 